\title{
Aeromagnetic Mapping of Iwo Region of Southwestern Nigeria for Lithostructural Delineation
}

\section{sciendo}

\author{
Okpoli C.C.* and Oludeyi D. \\ Department of Earth Sciences, Adekunle Ajasin University, Akungba-Akoko, Ondo State, Nigeria. \\ *Corresponding author e-mail: cyril.okpoli@aaua.edu.ng
}

\section{DOI: 10.2478/pjg-2019-0008}

\begin{abstract}
:
The IGRF filtered Aeromagnetic data over Iwo, southwestern part of Nigeria within the basement complex was subjected to reduction to magnetic equator filtering, residual filtering, upward and downward continuation filtering, automatic gain control filtering, tilt angle derivative, second vertical derivative, analytical signal and Euler deconvolution. This reveals the geologic information such as structural trend. Based on the result of the total magnetic intensity map, reduction to equator map, analytical signal map and residual magnetic intensity map, it can be concluded that; The rocks in the study area have a trend of approximately northeast- southwest direction as seen on the upward continuation map. Most of the delineated lineaments found within the study area strike mostly in NNE-SSW, NE-SW and NW-SE with minor trend of E-W and ENE-WSW direction. Structural lineament orientation suggested that they were products of Pan-African orogeny (NE-SW, NW-SE and NNE-SSW trends) and pre-Pan-African orogeny (NNW-SSE and E-W trend). The interpretation of the aeromagnetic dataset gave an insight into the regional geology and structural trends of the area.
\end{abstract}

Keywords: Aeromagnetic, Euler deconvolution, Derivatives, Filtering, lithostructures

\subsection{Introduction}

Aeromagnetic survey is one of the common types of geophysical survey carried out using a magnetometer aboard or towed behind an aircraft. The principle is similar to a magnetic survey carried out with a hand-held magnetometer but allows much larger areas of the earth's surface to be covered quickly for regional reconnaissance. The aircraft typically flies in grid-like pattern with height and line spacing determining the resolution of the data (and survey of the cost per unit area).

As the aircraft flies, the magnetometer records tiny variations in the intensity of the ambient magnetic field due to the temporal effects of the constantly varying solar wind and spatial variations in the earth's magnetic field, the latter being due to both the regional magnetic fields and the local effect of magnetic minerals in the earth's crust. From regional aeromagnetic data sets, information such as tectonic frame of the upper crust can be obtained. The patterns and amplitude of anomalies reflect the depth and magnetic character of crystalline basement, the distribution and volume of intrusive and extrusive volcanic rocks and the nature of boundaries between magnetic terrains. The application of aeromagnetic survey is as follows [1].

Aeromagnetic magnetic mapping serves the following purposes: Direct detection of deposits of certain iron ores. In oil exploration, aeromagnetic data can give information from which the depths to basement rocks can be determined and thus locate and define the extent of sedimentary basins. Sedimentary rocks however exert such a small magnetic effect compared with igneous rocks that virtually all variations in magnetic intensity measurable at the surface result from topographic or lithologic changes associated with the basement or from igneous intrusions. Recognition and interpretation of faulting, shearing, and fracturing not only as potential hosts for a variety of minerals, but also an indirect guide to epigenetic, stress related mineralization in the surrounding rocks. Identification and delineation of post-tectonic intrusive. Typical of such targets are zoned syenite or carbonatite complexes, kinerlites, tin-bearing granites, and mafic intrusions

Geophysics is defined as the physics of the earth and its surrounding atmosphere. That is to say, that geophysics has to do with all aspects of the physics of the earth, atmosphere and one might add today-space. The purpose of pure geophysics is to deduce the physical properties of the earth and its internal constitution from the physical phenomena associated with it, for instance the geomagnetic field, the heat flow, the propagation of seismic waves, the force of gravity etc.

On the other hand, the objective of applied geophysics is to investigate specific, relatively small scale and shallow features, which are presumed to exist within the earth crust. Among such features may be synclines and anticlines, geological faults, salt domes, undulation of the crystalline bedrocks under a cover of moraine, ore bodies, clay deposits etc. The investigation of such features very often has a bearing on practical problems of oil prospecting, location of water- bearing strata, mineral exploration, highway construction and civil engineering. The application of physics, in combination with geological information is the most or only satisfactory way towards a solution to these problems.

In mineral exploration, the structural surface interpreted from magnetic depth estimates is often the best available approximation to the true crystalline metamorphic/igneous basement configuration and estimate of basement depth sedimentary thickness is a primary exploration risks parameter. Specifically, the magnetic basement is very relevant in the application of magnetism to mineral exploration. Nigeria economy is solely dependent on the crude oil found on the Niger Delta region hence there is need to identify other possible source of mineral in other regions.

This study evaluates the aeromagnetic dataset of Iwo region total field aeromagnetic anomalies of the environment in order to map the magnetic lineament and estimate depth to basement thickness. The deduction reached after the consideration of qualitative and quantitative interpretation supported by geologic information of the area.

\subsection{DESCRIPTION OF STUDY AREA}

The study area is located within latitude $7^{\circ} 30^{\prime} \mathrm{N}$ to $7^{\circ} 33^{\prime} \mathrm{N}$ and longitude $4^{\circ} 35^{\prime} \mathrm{E}$ to $4^{\circ} 40^{\prime} \mathrm{E}$ in Southwestern Nigeria. The major roads are generally accessible through a good network of all seasonal roads and motorable track which link it with other part of the state. The area has minor roads and footpaths which makes them not motorable. Figure 1. shows the study area, which lies within the basement complex of South-Western Nigeria in the East of the West African Craton and West of the Congo Craton of late Precambrian to Early Paleozoic Pan African Orogenesis [2].

The geology of South-Western Nigeria comprises of rocks of the Precambrian Basement complex and the Cretaceous-Paleocene sediments. The Precambrian Basement occupies the greater parts of South-Western Nigeria where it continues in the West with the Dahomey Basin of the West African Craton. The Anambra Basin terminates the Basement complex in the East while it is bounded in the North by the Bida Basin at Lokoja, this Basement complex and its suites are overlain in the South by Cretaceous-Paleocene sediments at Ewekoro, Okitipupa, Abeokuta, Ifon and its Environs. The polymetamorphic migmatite-gneiss complex is composed largely of migmatites and gneisses of various compositions and amphibolites. Relict of meta-sedimentary rocks represented by medium to-high grade calcareous, pelitic and quartzitic rocks occur within the migmatites and gneisses, and they have been described as "Ancient Metasediments" by [3]. The migmatite-gneiss complex is considered to be the basement and isotopic ages varying from Liberian to Pan-African have been obtained from the rocks. The Pan-African ages have been interpreted as due to isotopic re-homogenization in preexisting rocks during the PanAfrican orogeny.

Further attempts on the classification of the Nigerian Basement Complex [4] distinguished four major petro-lithological units, namely: 
1. The Migmatite - Gneiss- Quartzite Complex

2. The Schist Belt (Metasedimentary and Metavolcanic rocks)

3. Older Granites and associated granitic rocks (The Pan-African Granitoids

4. Undeformed Acid and Basic Dykes or The minor felsic and mafic intrusives.
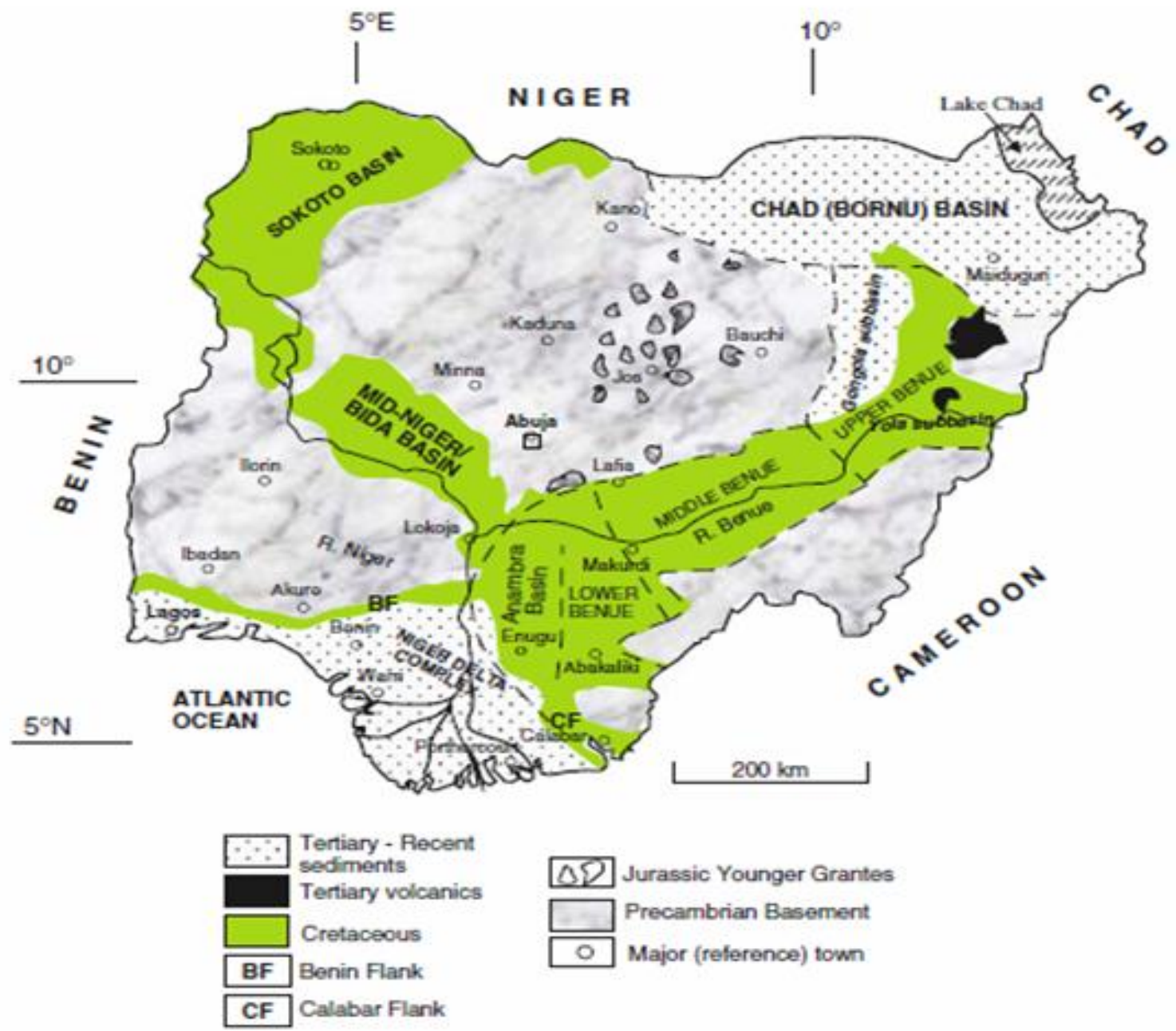

Figure 1: Geological map of Nigeria (Modified from [5])

Iwo area is located in the southern part of the Pan African reactivated terrane referred to as the Dahomeyide. The area is bounded to east by the West African Craton, to the southeast by the Congo Craton and northeast by Saharan Metacraton.

Various types of rocks occur throughout Osun State. The geology of most of Iwo region is covered by Iwo Sheet 242 on a scale of 1:100 000 (Geological Survey of Nigeria). The structural features exhibited by rocks of the area include foliation in the gneisses; lineation; folds; faults and joints. Rocks of the basement complex have been subjected to deformation during several orogeny cycles and it is difficult to differentiate between structures belonging to the separate periods of deformation. Minor folds are very common in the gneiss and schists and from all available evidence [6, 4], the basic geological structure of South-Western Nigeria is a complementary anticlinorium and synclinorium with northwards plunging axes. The quartzites did not escape the folding and refolding episodes which affected the entire region [7].

Major faults are rare in the basement complex generally, although there is a dominant fault in the area the Iwara fault which seems to control the mineralization within the amphibolite complex. "The talc-tremolite and marginal chlorite schists of the emphibolite complex occur along shear zones and faulted junctions which may belong to the porphyritic granite cycle of deformation". Furthermore, the granitisation which led to formation of potash granite gneisses in the variegated gneisses around Iwara can probably be related to the Iwara Fault. Jointing is a common feature in the area and is of tectonic origin. The major effects of these joints are reflected in structurally controlled drainage pattern and parallelism of the dolerite intrusions [8]. The rocks of the basement complex in the area have been subjected to intense regional metamorphism in which shearing stress was the dominant control resulting in the absence of minerals of high metamorphic grade. Migmatisation is widespread throughout the area reflected by rapid alternation of granite, biotite gneiss and biotite schists which grade into one another. Selective granitisation has resulted in biotite-rich layers in the gneisses being converted into porphyritic granite, while the leucocratic bands have been converted to aplitic granite. The various rock types in Osun State can be attributed to many factors. Several episodes of shearing. Faulting and metamorphism have already been recognized. Selected granitisation and localization of intrusive bodies coupled with rock transformation at shear zones have resulted in the preferred mineralisation patterns noticeable throughout the region. 


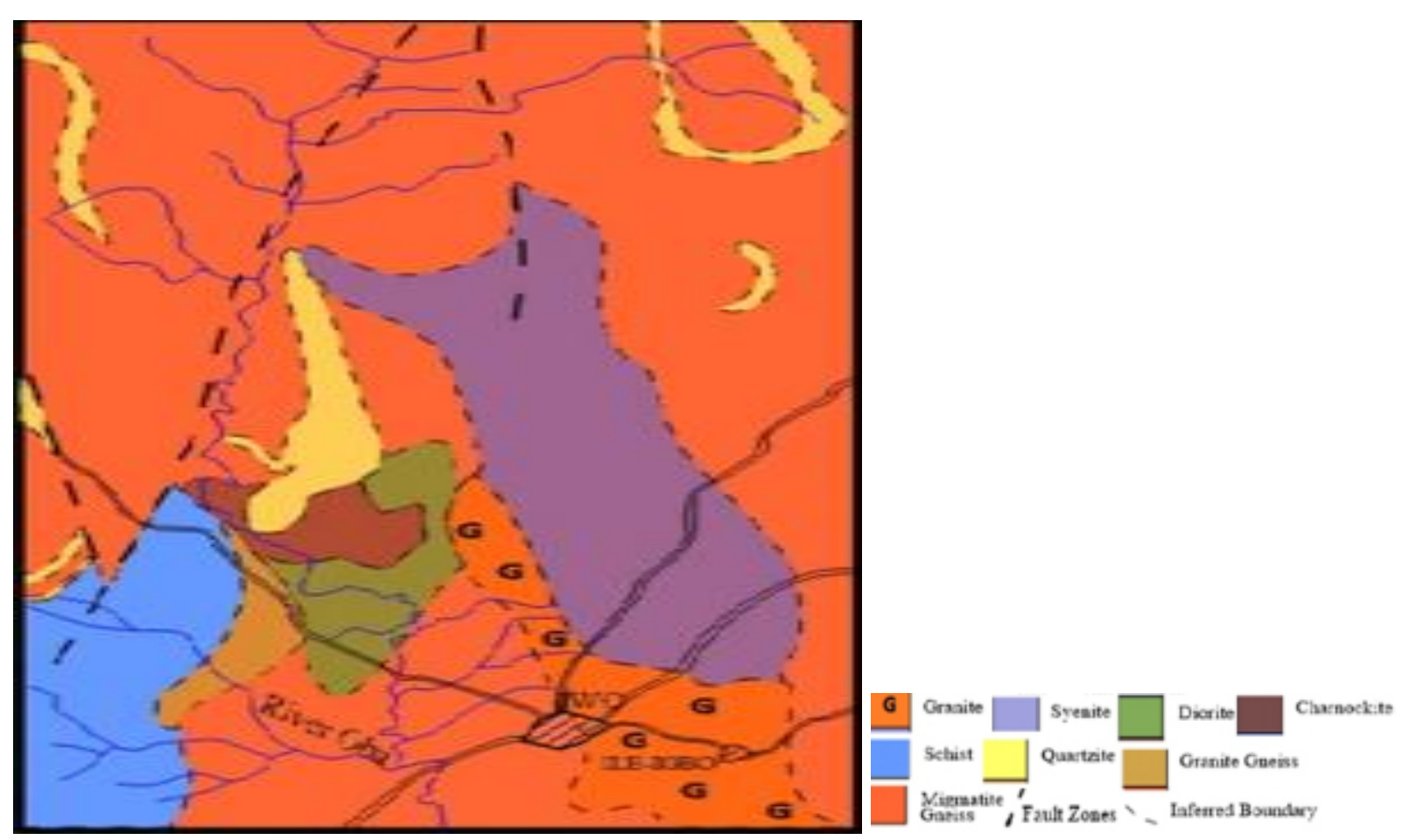

Figure 2: Geological map of Iwo area, southwestern Nigeria (modified from [9]

\subsection{METHODOLOGY}

The data was processed using Geosoft $®$ Oasis Montaj ${ }^{\mathrm{TM}}$ software, Surfer and Microsoft Excel softwares.

Data reductions such as: removal of near surface noise (NSN) using Butterworth filter, reduction to magnetic equator, regional field, residual field, automatic gain control (AGC), upward continuation, tilt-angle derivative (TDR), second vertical derivative (SVD), analytic signal (AS), radial average power spectrum (RAPS) and 3D Euler Deconvolution were performed for better result output. The data reductions and enhancements were done using the MAGMAP Step-byStep filtering processing. Figure 3 illustrate the schematic flowchart of the data processing and interpretation techniques.

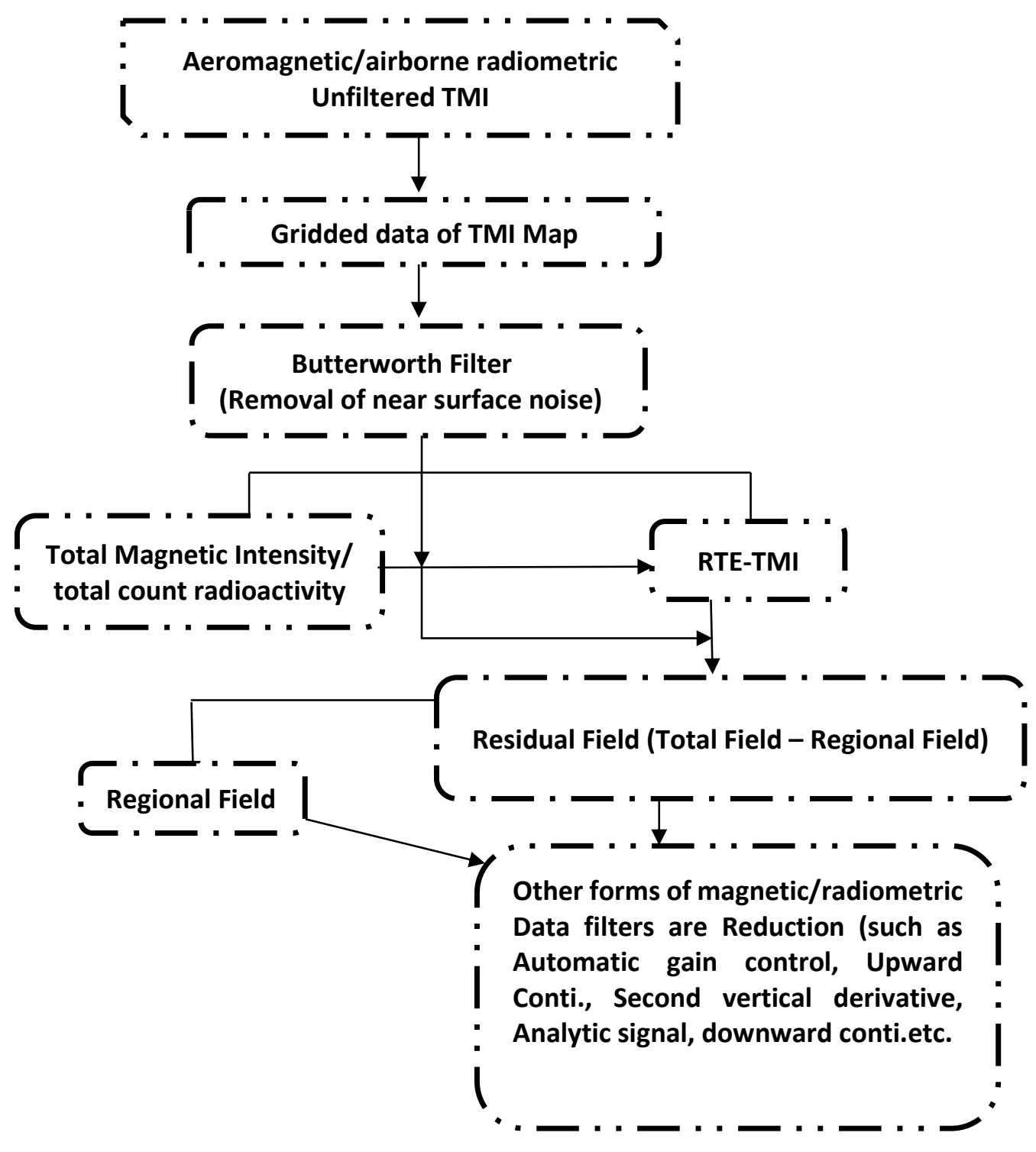


Figure 3: Data Processing and interpretation Flow Chat

\subsection{RESULTS AND DISCUSSION}

\subsection{Total Magnetic Intensity (TMI)}

From the map (Fig .4.1), there exist high intensity magnetic (97.060-128.496 nT) response at the Western and the eastern part of the map showing a trend of NE-SW direction. This high magnetic intensity was identified as A. At the central part of the map, intermediate magnetic intensity (61.837-87.017 nT) is seen around the high magnetic intensity and they were regarded as B. At the northern, south western parts of the map, fairly low magnetic intensity (27.220-55.810 $\mathrm{nT}$ ) were observed to be prominent. These observations were interpreted as C. Low magnetic intensity (-36.767- $23.885 \mathrm{nT})$ were seen to be prominent in the northwestern part of the map with some trending in E-W direction and some other in NE-SW direction. Small segment of the low magnetic intensity is observed at the southeastern striking in NE-SW direction. These low magnetic intensities were interpreted as D. Two faulting systems F1-F1'and F2-F2' were identified with trend of NNE-SSW and NE-SW respectively.

\subsection{Reduction to Magnetic Equator (RTE)}

From the map (Fig .4.2) there exist high intensity magnetic (87.291-123.068 nT) response at the eastern, western and southeastern part of the map trending almost in NE-SW direction. These high magnetic intensity responses were interpreted as A. Intermediate magnetic intensity (61.076- 78.586 nT) were seen around the high magnetic intensity at the central part of the map and they were regarded as B. At the northern, south western parts of the map, fairly low magnetic intensity (29.210- 57.006 nT) were observed to be prominent. These observations were interpreted as C. Low magnetic intensity (-31.759- $22.812 \mathrm{nT})$ were seen to be prominent in the northwestern part of the map with some trending in E-W direction and some other in NE-SW direction. Small segment of the low magnetic intensity is observed at the southeastern striking in NE-SW direction. These low magnetic intensities were interpreted as D.

Three faulting systems F1-F1', F2-F2' and F3-F3' are identified. The reduction to equator map (Fig. 4A) in comparison with the total magnetic map (Fig. 4B) shows no differences in terms of structures and magnetic bodies.
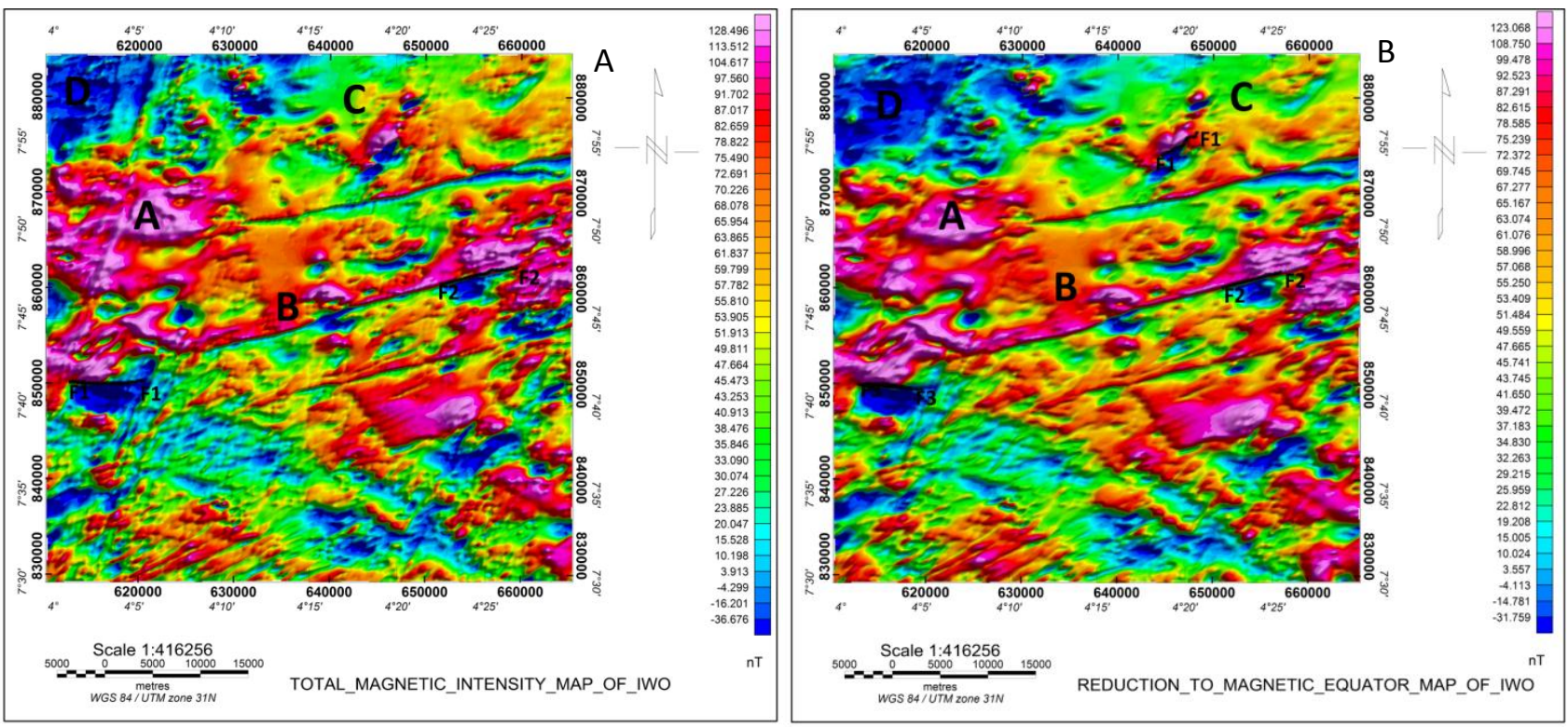

Figure 4: Total Magnetic Intensity (TMI) and Reduction to magnetic equator Images.

\subsection{Residual Magnetic Intensity (RMI)}

On the map (Fig. 5), high magnetic intensity (90.404-122.938 nT) were noticed at the northeastern part of the map showing two different trends, E-W and NESW trends. Also, at the southestern region of the map, there occurs this high magnetic intensity. Small segment of the high magnetic intensity is observed at the northwestern part of the map trending in NE-SW direction. These high magnetic intensities were identified as A. At the central part of the map, intermediate magnetic intensity (61.002-75.202 nT) was observed trending in NE-SW direction. They were also observed at the northeastern part of the map. This observation was classified as B. Fairly low magnetic intensity (29.245-47.043 nT) is seen at the south, southwestern, northeastern, northern and central part of the map and they were interpreted as C. At the northweastern part of the map, there exist low magnetic intensity (-31.070-22.828 nT) showing two different trends, E-W and NE-SW trends. Small segment of the low magnetic Intensity is observed at the southern part of the map trending in NE-SW direction. Two faulting systems F1-F1' and F2-F2' are identified with trend of NE-SW and E-W respectively. 


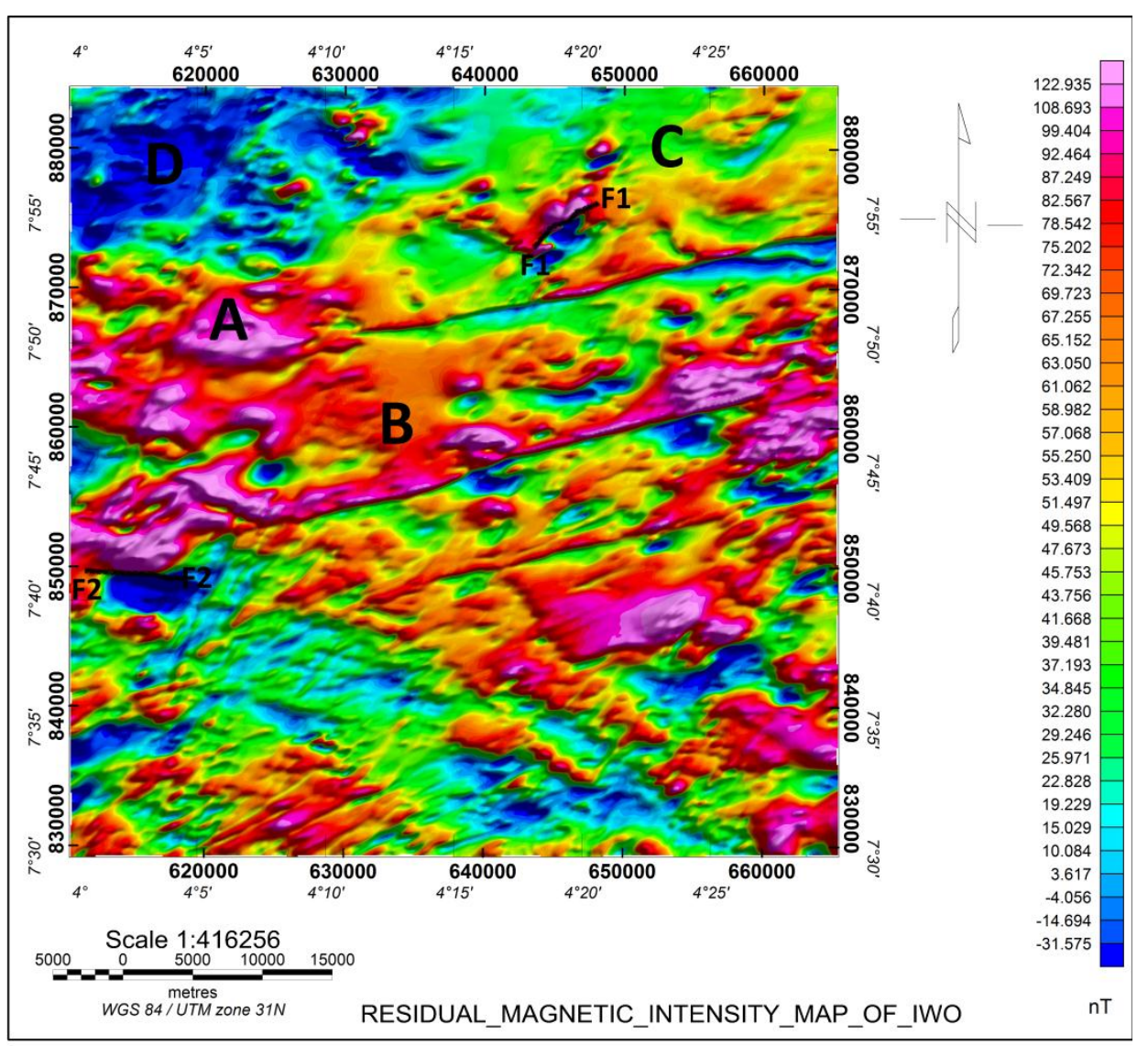

Figure 5: Residual magnetic intensity Map

\subsection{Automatic Gain Control (AGC)}

In Figure 6, display magnetic intensity with positive intensity signals that ranged from 362.342 to 379.370 and -275.632 to -35.740 for negative anomalies. The result in figure 4.4 gives a sensible view of well aligned anomalous structures with positive intensity signal that ranged from 362.342 to 379.370 for high anomalous and -275.632 to -35.740 for low anomalous. Point A, B AND C indicates the long lineaments/faults with moderate magnetic intensity clearly obvious compared to RTE map (Fig. 4B). the anomaly marked 0 exhibit different lithology when compared to the anomaly surrounding it. Over ten lineaments were observed on the map and they all show three different trends in general.

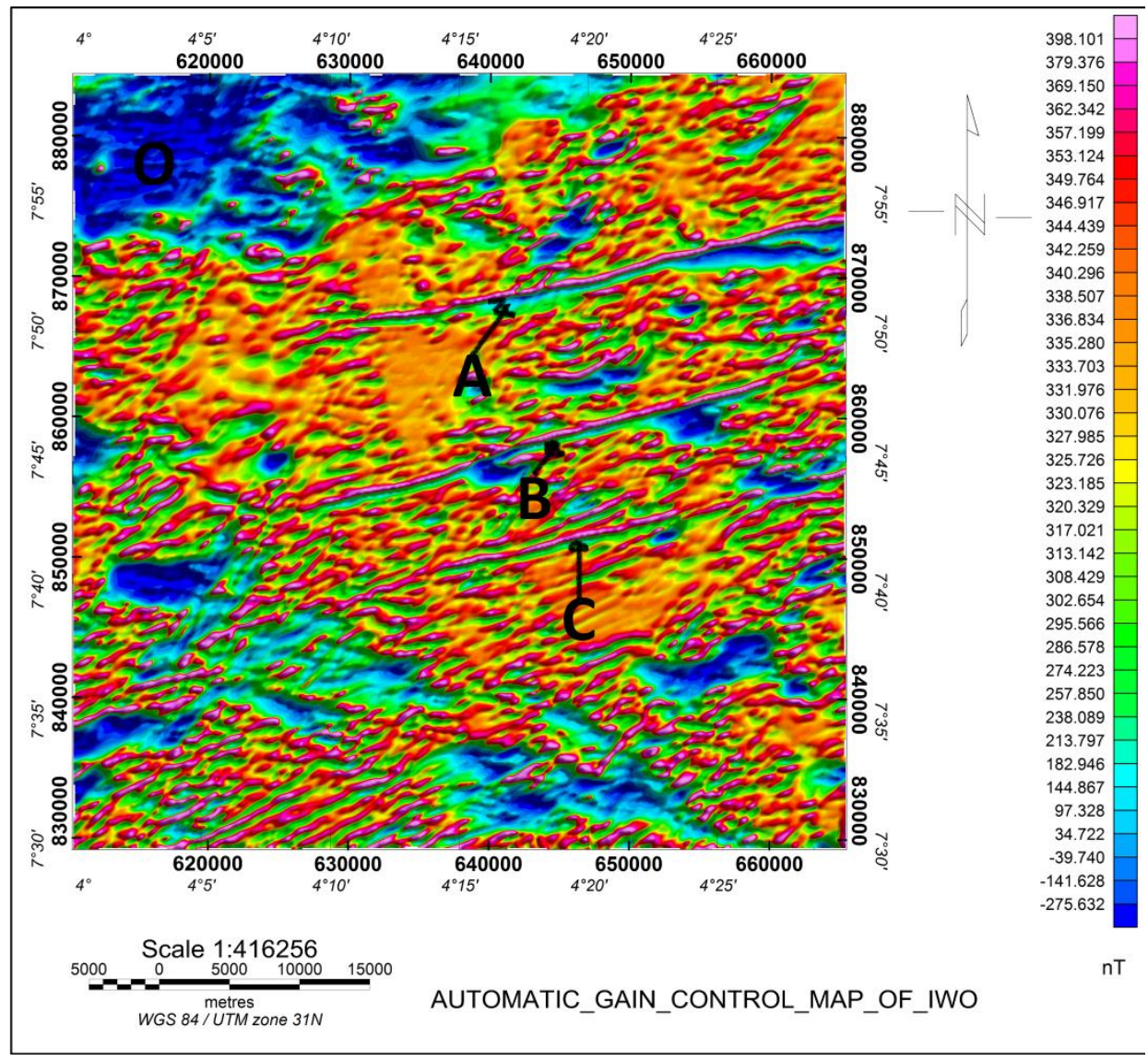


Figure 6: Automatic gain control Map

\subsection{Upward Continuation}

Upward continuation filter was used in suppressing the effect of shallow anomalies, in order to obtain information on deeper anomalies. Figures $(7 \mathrm{a}$, 7b and $7 \mathrm{c})$ show the RTE grid continued upward to $500 \mathrm{~m}$ and $1000 \mathrm{~m}$ and $2000 \mathrm{~m}$ respectively; i.e. they show images of the magnetic intensity that would be obtained assuming the data were recorded at heights of $500 \mathrm{~m}, 1000 \mathrm{~m}$ and $2000 \mathrm{~m}$ higher than the original datum the data was collected. The linear structure showed by these images at the western part of the map trending northeast direction are pronounced and seen beyond $0.5 \mathrm{~km}$. These structures diminish as the depth of continuation increases to $1 \mathrm{~km}$. The positive anomalous zones at the western, eastern and to some part of the southeastern axes are deep-seated basement rocks with high magnetic mineral constituents. The upward continued images revealed that the regional trend of the rocks in the study area is in northeast-southwest direction, as distinctively seen in Figure 7c.
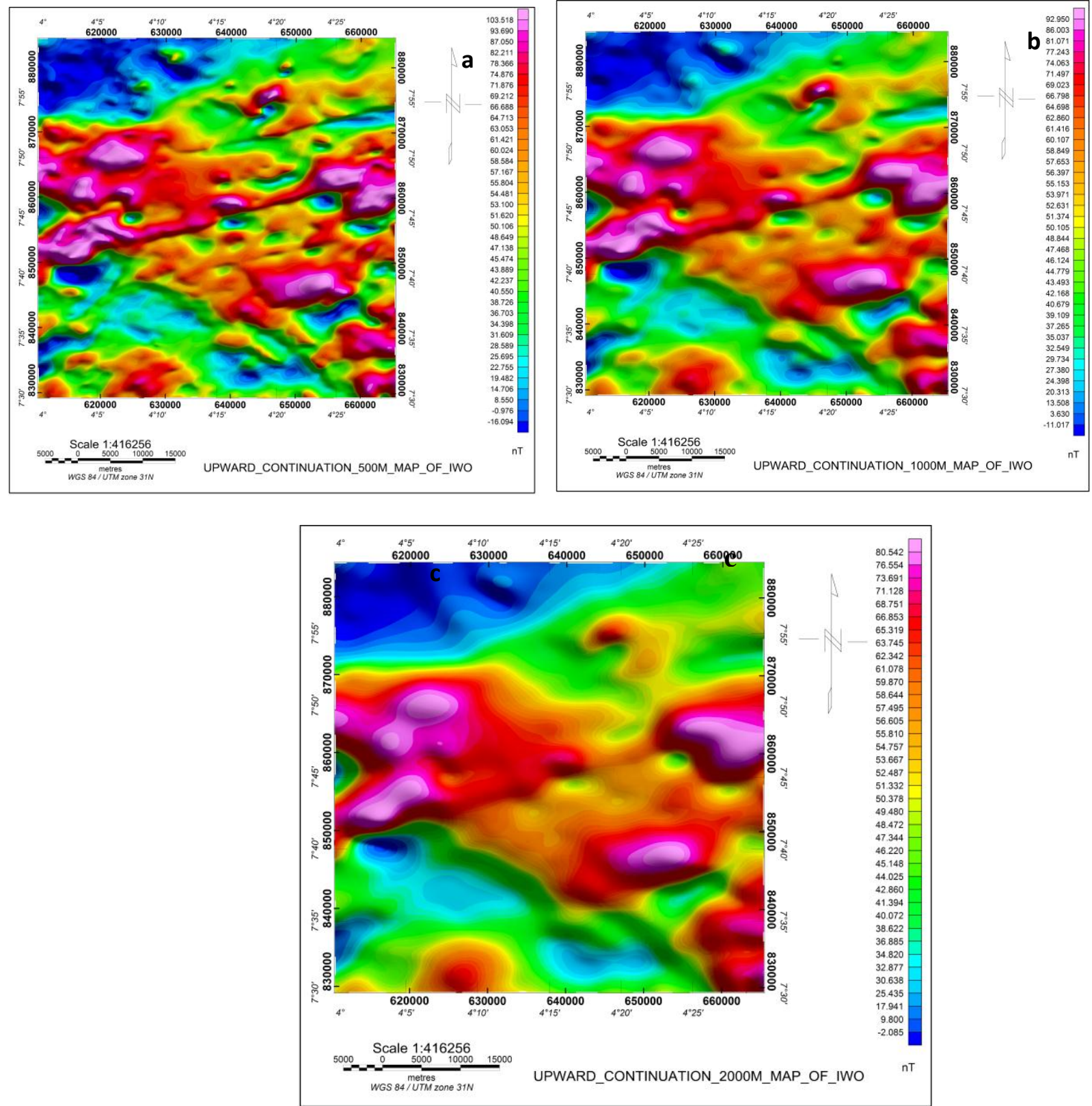

Figure 7: Upward continuation Maps (a)500 m (b) 1 Km and (c) $2 \mathrm{Km}$

\subsection{Downward Continuation Filter}

Downward continuation filter helps to calculate the magnetic field with the measurement plane closer to the sources [10]. Reducing the spatial overlap of anomalies and thus be more easily distinguished from the other. Downward continuation, a low cut and optimum filter were also applied to enhance responses emanating from shallower sources; this was achieved by moving the detector closer to the source. The principle is such that short wavelength signals are likely to originate from shallow sources, hence signals originating from a particular depth source could be selected based on wavelength.

Figures $8 \mathrm{a}, 8 \mathrm{~b}, 8 \mathrm{c}$ shows the RTE (grid) continued downward $20 \mathrm{~m}, 50 \mathrm{~m} ; 100 \mathrm{~m}$ i.e. it shows image of the magnetic intensity that would be obtained assuming the data were recorded at height of $20 \mathrm{~m}, 50 \mathrm{~m}$ and $100 \mathrm{~m}$ lower than the original datum the data was collected. The downward continuation map (Fig $4.6 \mathrm{a}$, $4.6 \mathrm{~b}$, 4.6c) in comparison with the RTE image shows similar features as seen in the RTE image (Fig.4.2). From the downward continuation map, it is seen that the boundaries of the different lithofacies were not well demarcated compared to the upward continuation.

From the map, three major lineaments (faults and joints) systems were identified on this image by observing the abrupt changes between the positive and negative magnetic anomalies. 

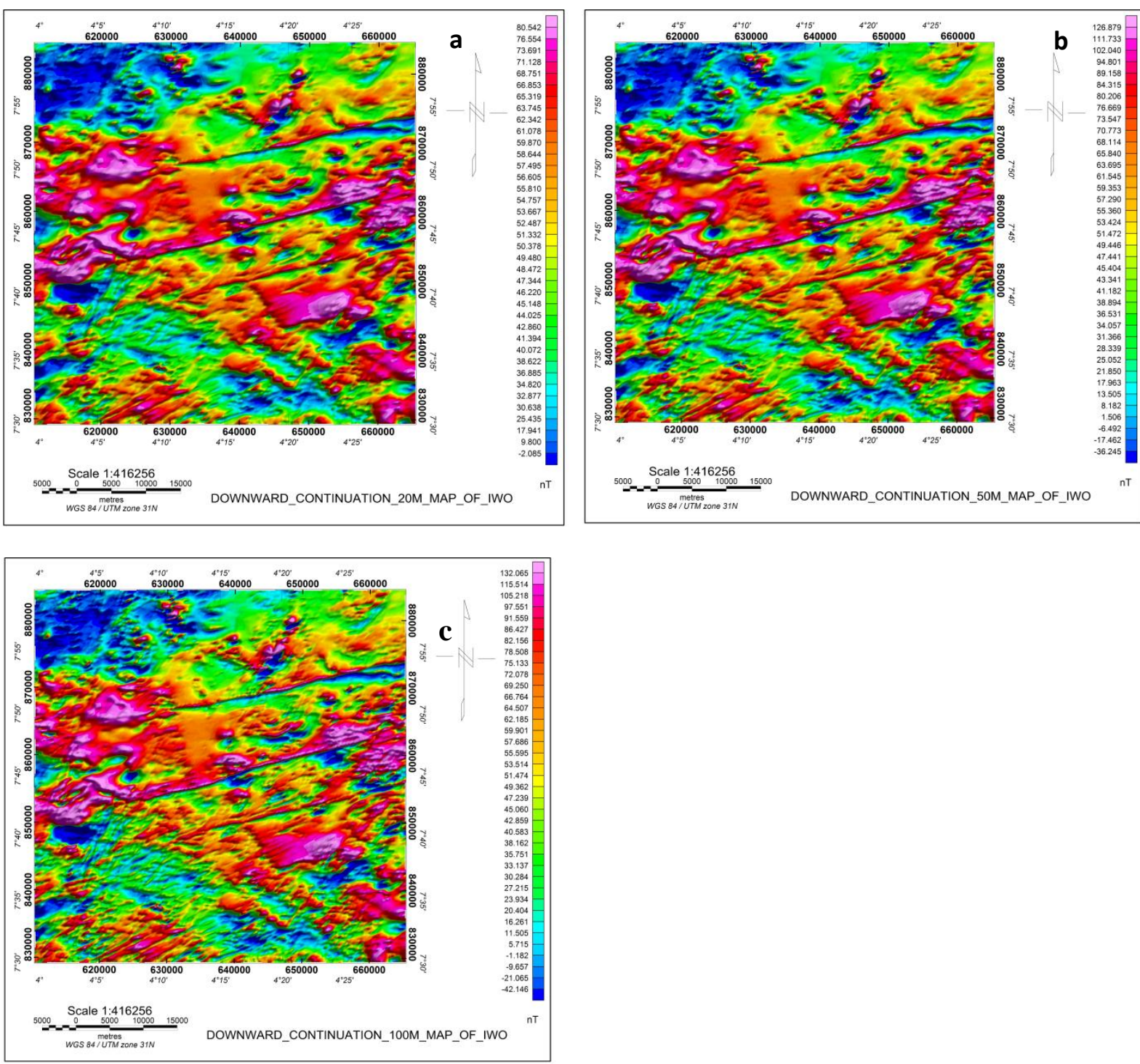

Figure 8: Downward continuation Maps (a)20 m (b) $50 \mathrm{~m}$ and (c) $100 \mathrm{~m}$

\subsection{Second Vertical Derivative (SVD)}

Second Vertical derivatives of magnetic fields, because of their high resolving power are often very useful in interpreting magnetic anomalies. The second vertical derivatives filter sharpens the edges of anomalies which aid in locating their positions.

The second vertical derivatives (SVD) map (Fig. 9) shows magnetic intensity range between $-0.138 \mathrm{nT} / \mathrm{m}-0.126 \mathrm{nT} / \mathrm{m}$. The second vertical derivatives filter shows relative similar features with the analytical signal filter map. High magnetic anomaly is observed around the southwestern trending vertically towards the western part of the area. The high magnetic anomaly corresponds to the schist and migmatite majorly when compared to the geological map of the area (Fig. 2). The mineralogy of the rocks can also account for this high magnetic anomaly. Rocks rich in ferromagnesian minerals tend to give rise to high magnetic signatures. 
ISSN: 2576-6732 (Print)

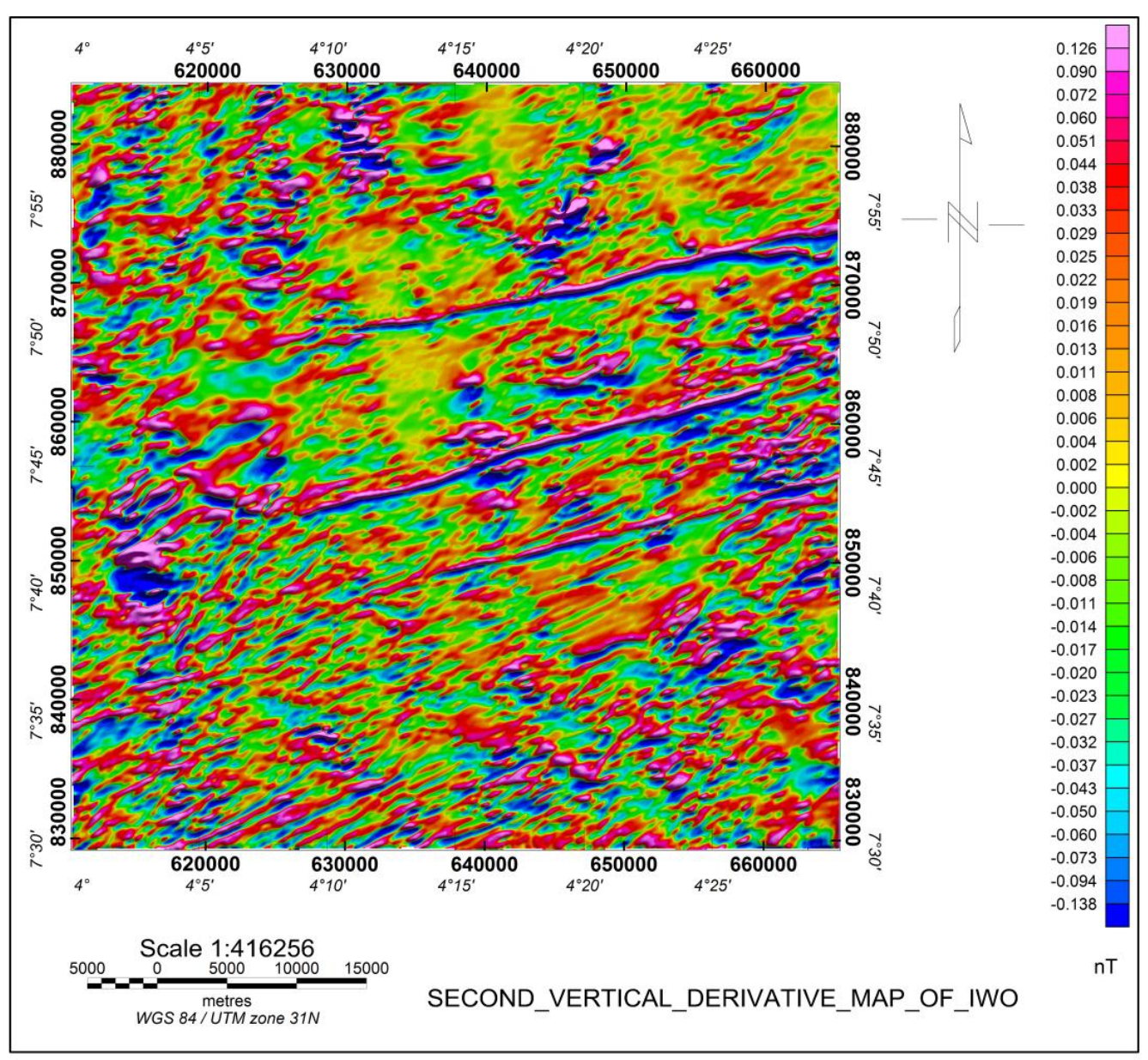

Figure 9: Second Vertical Derivative Map 


\subsection{Tilt Angle Derivatives}

The total horizontal derivative (THDR) was used for this study because this method was designed to image faults and contact features which makes it well suited for this study as we intend to delineate faults in the Pan-African and Older granites which may contain mineralized pegmatites as well as mineralized shear zones or alteration zone

To determine geological structures such as faults and folds and to enhance both weak and strong magnetic anomalies of the area, the TDR filter was applied to the RTE grid. Fig. 10a and 10b displayed most structural feature of the area such as the faults. The magnetic grey shaded colour TDR map (Fig. 10a) shows subtle anomalies and structures present in the study area. From the map, one can easily interpret different geological structures present on the map (Fig. 10b).

THDR is a powerful method because it brings out the edges of the structures and they appear like rail lines along narrow features. The output shows the NE-SW and NW-SE structures in the data clearly defined with NE-SW indicated with blue lines and NW-SE with yellow line. The major structural lineament trends were NNE-SSW, NE-SW and NW-SE, other minor structural trends on the Automatic Gain Control (AGC), Tilt angle Derivative and Analytic Signal map are E-W and ENE-WSW.
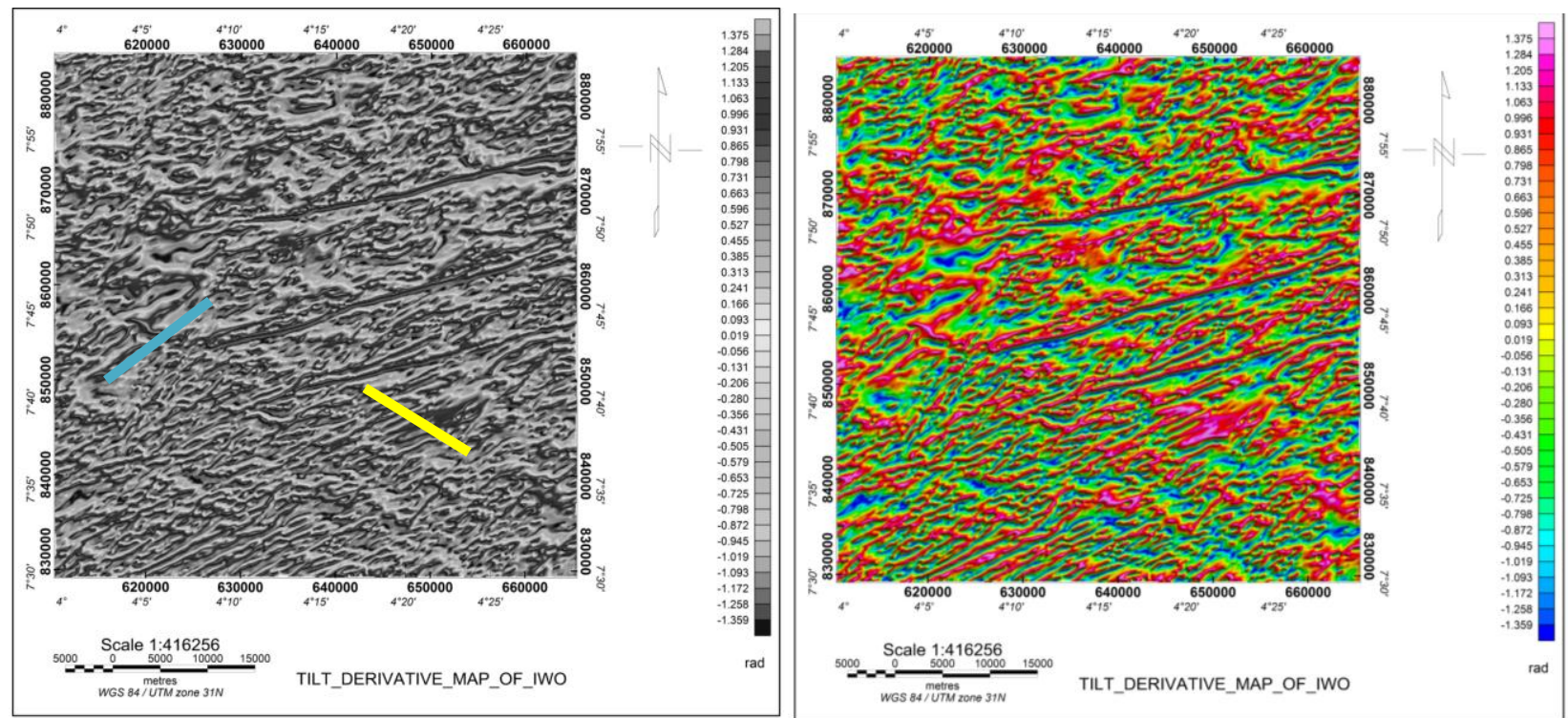

Figure 10: Tilt Derivative Maps (a) Grey scale (b) High resolution Map

\subsection{Analytical Signal (AS)}

From the map (Fig. 11), high magnetic anomalous zone ( $>0.105)$ which is interpreted, intermediate magnetic anomalous zone (ranges from 0.041 to 0.096$)$ and low magnetic anomalous zone $(<0.037)$. These three zones are likely to be related to zones of weaknesses based on the magnetic amplitude. The high amplitude response is seen to have been separated by regional lineament at the eastern region of the map trending in NE-SW direction from the intermediate amplitude. The intermediate, is observed across every part of the map extending towards the central region. 


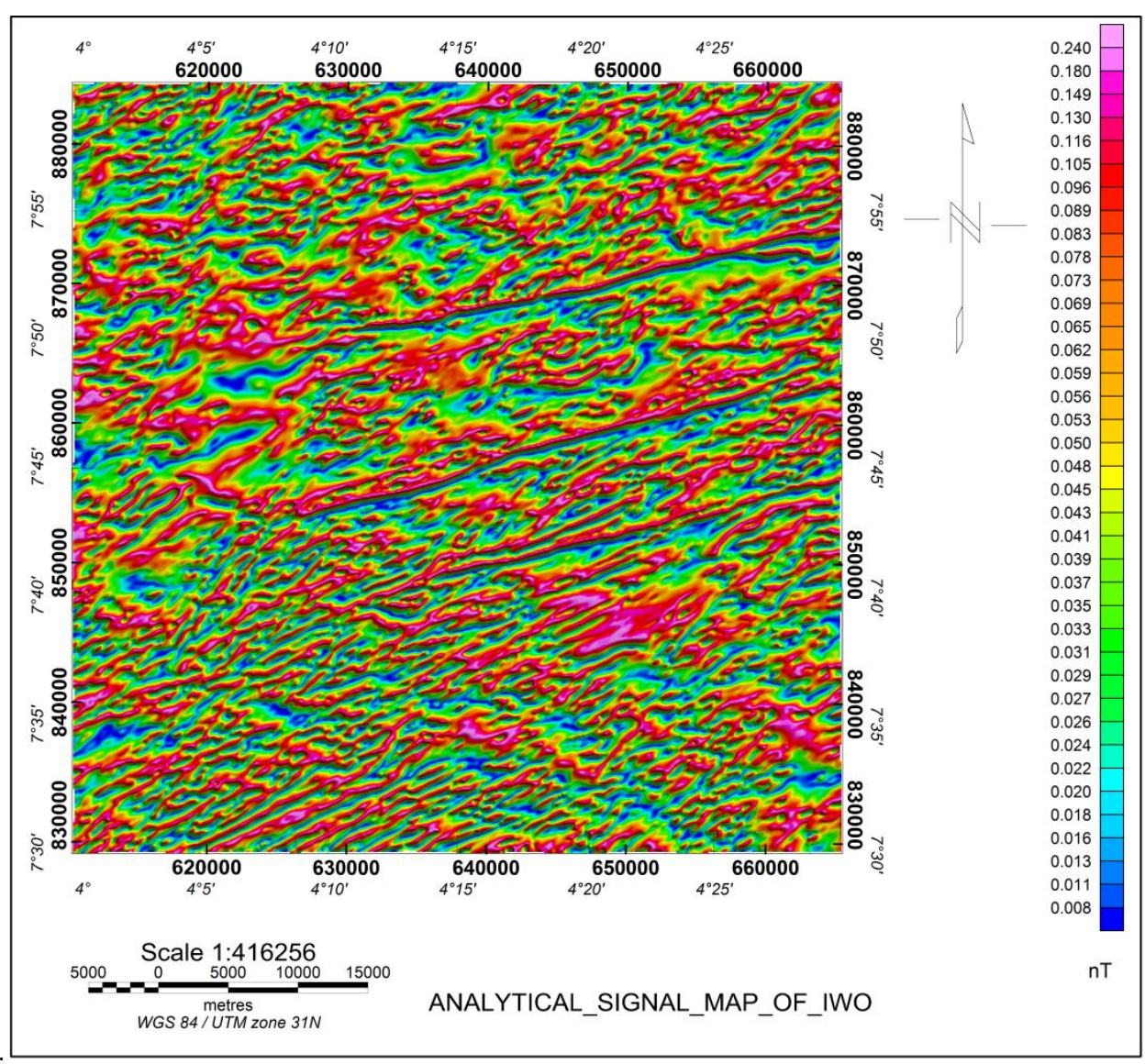

Figure 11: Analytical Signal Map

Structural Trend Analysis

The major structural lineament trends were NNE-SSW, NE-SW and NW-SE, other minor structural trends on the Automatic Gain Control (AGC), Tilt angle Derivative and Analytic Signal map are E-W and ENE-WSW.

\subsection{Euler deconvolution}

The use of Euler deconvolution as an interpretation tool to determine source location of potential fields anomalies. Thompson, 1982 developed the technique and applied it to profile data, and Reid et.al., 1990 developed the more widely used version for grid-based data. Euler deconvolution method is used to estimate the locations and depths for several linear subsurface features such as (lineaments, geological contacts, faults, dikes, sills). So that, it requires knowledge about the type and nature of the causative body which can be achieved by defining the structural index [11]. The Euler deconvolution was applied to the RTE-TMI map at structural index 0.0 to obtain better solutions shown in (Fig. 12 ) with an average error in depth estimation less than the required maximum $15 \%$ tolerance and window size, and the result with the least unreal solutions was adopted. The linear forms with the same depths generally corresponds to faults. Each structural index represent different model. The SI for any given anomaly may be determined indirectly by seeking the SI value that yields least local perturbation of the calculated background value (Barbosa et.al., 1999). The application of extended Euler deconvolution creates a large volume of information.

Structural index 0.0 is modeled as contact for the magnetic map figure 12 to locate and determine the contact depth. The magnetic map depth ranges from less than $-446.853 \mathrm{~m}$ to $2073.575 \mathrm{~m}$. the SI 0.0 to some extent it shows some structural trends of the area. 


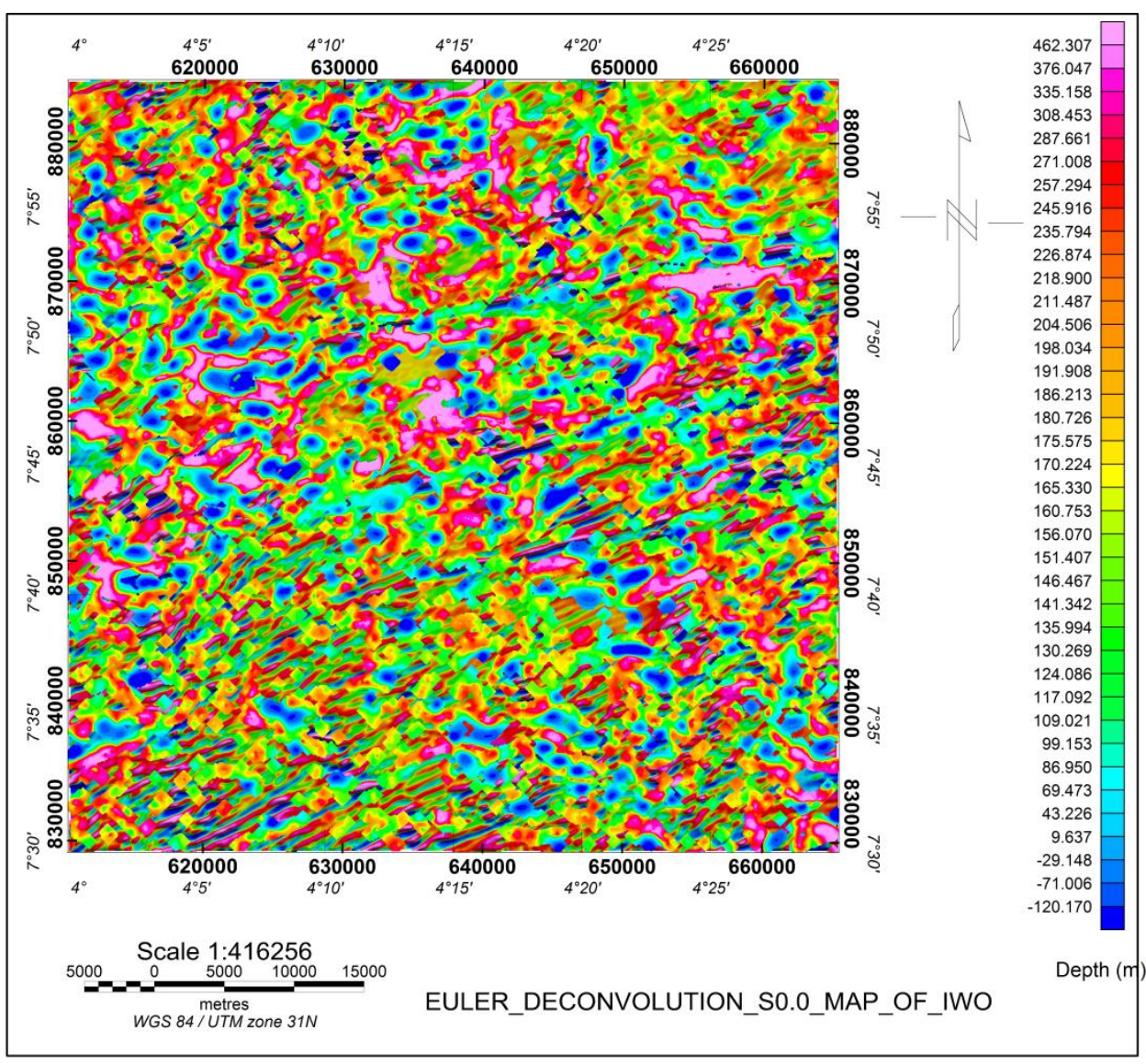

\subsection{Conclusion}

Based on the result of the total magnetic intensity map, reduction to equator map, analytical signal map and residual magnetic intensity map. The rocks in the study area have a trend of approximately northeast- southwest direction as seen on the upward continuation map. Most of the delineated lineaments found within the study area strike mostly in NNE-SSW, NE-SW and NW-SE with minor trend of E-W and ENE-WSW direction. Structural lineament orientation suggested that they were products of Pan-African orogeny (NE-SW, NW-SE and NNE-SSW trends) and pre-Pan-African orogeny (NNW-SSE and $\mathrm{E}-\mathrm{W}$ trend). The interpretation of the aeromagnetic dataset gave an insight into the regional geology and structural trends of the area. Ground magnetic survey is highly recommended to confirm the delineated structure and lithology.

\section{References}

[1] R.G. Allis, "Geophysica

anomalies

over

epithermal

systems",

Journal

of

Geochemical

[2] M.A. Rahaman, "Review of the basement geology of south-western Nigeria. In: Oluyide, P.O., Mbonu, W.C., Ogezi, A.E., Egbuniwe, I.G., Ajibade, A.C. and Umeji, A.C. (Eds.), Precambrian Geology of Nigeria", Geological Survey of Nigeria, Kaduna, pp. 313-324, 1976.

[3] M.O. Oyawoye, "The Geology of the Nigeria Basement Complex, lotirn", Nigeria Min. Geol. and Met. Soc, vol. 1, no. 2, pp. 87-102, 1964.

[4] A.E.O. Ogezi, "Geochemistry and Geochronology of Basement

from

Northwestern Nigeria", Ph.D. thesis. Leeds University, 1977.

[5] N.G. Obaje, "The Benue Trough Geology and Mineral Resources of Nigeria", Springer, Dordrecht Heidelberg, New York, London, ISBN 3-540-92684-4 2009.

[6] F.S. Grant, "Aeromagnetic, geology and ore environments, In. magnetite, in igneous, sedimentary and metamorphic rocks: an overview" Geoexploration, vol. 23, pp. 303 - 333, 1971.

[7] O.A. Okunlola, "Metallogeny of Tantalum-Niobium mineralization of Precambrian pegmatites of Nigeria", Mineral Wealth, vol. 137, pp. 38-50, 2005.

[8] M.A.O. Rahaman, T.R. Ajayi, l.O. Oshin, E.O.L. Asubiojo, "Trace clement geochemistry and geotcctonic setting of lle-llcsha Schist Belt", Precam. Geol. Of Nigeria, pp. 241-256, 1988.

[9] A. Adetunji, V.O. Olarewaju, O.O. Ocan, L. Macheva, V.Y. Ganev, "Geochemistry and U-Pb zircon geochronology of Iwo quartz potassic syenite, southwestern Nigeria: Constraints on petrogenesis, timing of deformation and terrane amalgamation", Precambrian Research, vol. 307, 125-136, 2018.

[10] R.S. Pawlowski, "Preferential continuation for potential-field anomaly enhancement", Geophysics, vol. 60, pp. 390-398, 1995.

[11] A. Salem, S. Williams, J. Fairhead, D. Ravat, R. Smith, "Tilt-depth method: a simple depth estimation method using first-order magnetic derivatives.

The Leading Edge, vol. 26, pp. 1502-1505, 2007. 